e-ISSN 1980-5918

Fisioter. Mov., Curitiba, v. 30, n. 4, p. 805-811, Oct./Dec. 2017

Licenciado sob uma Licença Creative Commons

DOI: http://dx.doi.org/10.1590/1980-5918.030.004.A016

(c) ()

\title{
Functional capacity and mental state of patients undergoing cardiac surgery
}

\author{
Capacidade funcional e estado mental de \\ pacientes submetidos à cirurgia cardíaca
}

\author{
Bruna Corrêa, Dannuey Machado Cardoso*
}

Universidade de Santa Cruz do Sul (UNISC), Santa Cruz do Sul, RS, Brazil

\begin{abstract}
Introduction: Cardiovascular diseases are a serious public health problem in Brazil. Myocardial revascularization surgery (MRS) as well as cardiac valve replacement and repair are procedures indicated to treat them. Thus, extracorporeal circulation (ECC) is still widely used in these surgeries, in which patients with long ECC times may have greater neurological deficits. Neurological damage resulting from MRS can have devastating consequences such as loss of independence and worsening of quality of life. Objective: To assess the effect of cardiac surgery on a patient's mental state and functional capacity in both the pre- and postoperative periods. Methods: We conducted a cross-sectional study with convenience sampling of subjects undergoing MRS and valve replacement. Participants were administered the Mini-Mental State Exam (MMSE) and the Duke Activity Status Index (DASI) in the pre- and postoperative periods, as well as before their hospital discharge. Results: This study assessed nine patients (eight males) aged $62.4 \pm 6.3$ years with a BMI of $29.5 \pm 2.3 \mathrm{~kg} / \mathrm{m}^{2}$. There was a significant decrease in DASI scores and $\mathrm{VO}_{2}$ from preoperative to postoperative status $(\mathrm{p}=0.003$ and $p=0.003$, respectively). Conclusion: This study revealed a loss of cognitive and exercise capacity after cardiac surgery. A larger sample however is needed to consolidate these findings.
\end{abstract}

Keywords: Cardiovascular Diseases. Thoracic Surgery. Extracorporeal Circulation. Motor Activity. Cognition.

* BC: BS, e-mail: brunacorrea.fisio@gmail.com

DMC: MS, e-mail: dannuey@yahoo.com.br

Fisioter Mov. 2017 Oct/Dec;30(4):805-11 
Resumo

Introdução: As doenças cardiovasculares são um grave problema de saúde pública no Brasil, sendo as cirurgias de revascularização do miocárdio (CRM) e reparações ou trocas valvares, indicadas para tratamento destas doenças. Assim, a circulação extracorpórea (CEC) ainda é muito utilizada nestas cirurgias, onde pacientes com tempo elevado de CEC podem apresentaram maiores déficits neurológicos. Os danos neurológicos decorrentes da CRM podem ter consequências devastadoras como perda de independência e piora na qualidade de vida. Objetivo: Avaliar o efeito da cirurgia cardíaca sobre o estado mental e capacidade funcional de pacientes cardiopatas nos períodos pré e pós-operatório. Métodos: Estudo transversal, com amostra de conveniência, onde os sujeitos foram submetidos à CRM e troca valvar. Foram aplicados os questionários Mini-Mental State Exam (MMSE) e o Duke Activity Status Index (DASI), no período pré-operatório e antes da alta hospitalar. Resultados: Foram avaliados nove pacientes (oito homens) com idade 62,4 $\pm 6,3$ anos e IMC 29,5 $\pm 2,3 \mathrm{Kg} / \mathrm{m} 2$. Observou-se uma queda significativa no DASI e no $\mathrm{VO}_{2}$ no período pós em relação ao pré-operatório ( $p=0,003$ e $p=0,003$, respectivamente). Conclusão: No presente estudo constatou-se uma perda da capacidade cognitiva e de exercício após a cirurgia cardíaca. No entanto, um aumento do tamanho amostral faz-se necessário para consolidação dos resultados.

Palavras-chave: Doenças Cardiovasculares. Cirurgia Torácica. Circulação Extracorpórea. Atividade Motora. Cognição.

\section{Introduction}

Cardiovascular diseases are a serious public health problem in Brazil. The main clinical manifestations result from atherosclerotic processes such as cerebrovascular disease, peripheral vascular disease, cardiac ischemia and coronary atherosclerotic disease or coronary artery disease (CAD) $(1,2)$. Smoking, high levels of low density lipoprotein (LDL), low levels of high density lipoprotein (HDL), diabetes mellitus, systemic arterial hypertension, family history, lifestyle, obesity, sedentary lifestyle and heavy alcohol intake are the main risk factors that contribute to the development of the disease $(3-5)$.

Heart valve diseases may, however, be congenital, acquired during life or result from an infection. There are two categories of the disease, namely: stenosis and regurgitation or insufficiency. Severe aortic stenosis is the most common heart valve disease in older adults in western society. It is associated with reduced quality of life and increased mortality. Heart valves can be replaced by mechanical or biological prostheses (6-8).

Myocardial revascularization surgeries (MRS) as well as valve replacement or repair are considered to be major surgeries that require immediate postoperative intensive care. Extracorporeal circulation (ECC) is widely used in different types of cardiac surgery and can produce a systemic inflammatory response, releasing substances that impair coagulation and immune response. Thus, patients with long ECC times are more likely to have greater neurological deficits $(9,10)$.

Neurological damage resulting from ECC can have devastating consequences such as loss of independence and worse quality of life. However, the most important factor associated with impairment of functional independence is duration of ICU stay and mechanical ventilation. These factors contribute to impairing the performance of daily activities such as personal hygiene and feeding after hospital discharge (11 - 13).

The functional autonomy required to perform activities of daily living may be reduced or lacking due to some types of chronic diseases, traumatic or surgical processes. The assessment of functional capacity is important in measuring the impact of disease on the patient's life and it is also a factor in diagnosis and prognosis, as well as a strong predictor of mortality (14).

Previous studies indicate that patients undergoing heart surgery have reduced functional capacity in the immediate postoperative period. Functional capacity, however, can be recovered 1-3 months after the procedure through a cardiac rehabilitation program (CRP) $(15,16)$. 
Given the importance of cardiac surgery in correcting myocardial ischemia to relieve symptoms, improve quality of life and facilitate a return to daily life activities, this study aimed to assess the effect of cardiac surgery on the mental state and functional capacity of patients with heart disease.

\section{Methods}

We conducted a cross-sectional study with convenience sampling of subjects undergoing MRS and valve replacement in a regional teaching hospital between September and December, 2015.

This study included patients aged 18 years or older who had been admitted to the aforementioned hospital with a diagnosis of CAD or valvular heart disease, had undergone cardiac surgery, provided written informed consent, were clinically stable postoperatively and had participated in a CRP during hospital stay. Individuals who were not physically and/or mentally capable of completing the assessments were excluded from the study. This study complied with resolution CNS/MS 466/2012 regarding ethics in research with human beings and was approved by a Research Ethics Committee (protocol number 1.228.400).

First, we collected patients' identification data, clinical status information, surgical procedure data, information on intraoperative complications and length of ICU and hospital stay from their medical records and recorded on Surgical Monitoring Sheets. Next, the following questionnaires were administered to participants preoperatively and postoperatively before hospital discharge: the Mini-Mental State Exam (MMSE) and the Duke Activity Status Index (DASI).

The MMSE consists of 11 questions divided into 2 parts. Evaluate temporal orientation ( 5 points), spatial orientation ( 5 points), immediate memory ( 3 points), attention/concentration (5 points), delayed recall ( 3 points), naming ( 2 points), verbal repetition (1 point), verbal comprehension ( 3 points), writing (1 point), language ( 8 points) and reading a sentence (1 point), and constructional praxis (1 point). Scores range from 0 (cognitive impairment) to 30 (best cognitive capacity). Scores between 30 and 25 are considered normal. Scores below 25 are considered indicative of severe ( $<10$ points), moderate $(10-17$ points) or mild cognitive loss (18-24 points) $(11,17,18)$.

Functional capacity was assessed with the Duke Activity Status Index (DASI). The DASI has been especially used in patients with CAD, heart failure, myocardial ischemia and infarction. It consists of 12 items that assess activities of daily living such as personal care, ambulation, household tasks, sexual function, and recreational activities. Each item is weighed based on the known metabolic cost (MET) of each activity. The final score ranges from 0 to 58.2 points. The higher the score, the better the functional capacity. $\mathrm{VO}_{2}\left(\mathrm{~mL} \bullet \mathrm{kg}^{-1} \bullet \mathrm{min}^{-1}\right)$ is estimated according to the following multiple regression equation: $\mathrm{VO}_{2}=0.43 \times \mathrm{DASI}+9.6$. Both questionnaires were administered preoperatively and immediately before hospital discharge $(14,19)$.

Sample size was calculated based on a previous study by Morais et al. (18). It was calculated that a sample size of 9 would be sufficient to detect a three-point difference in the mean DASI score between the preand postoperative periods, with a standard deviation of 4 points, $80 \%$ power and a p-value less than 0.05 .

All statistical analyses were conducted using SPSS (version 20.0). Normality was tested using ShapiroWilk's tests. The data are shown as mean \pm standard deviation. Pre- and postoperative variables were compared using paired Student's t test. The level of statistical significance was set at $\mathrm{p}<0.05$.

\section{Results}

This study assessed nine patients (eight males and one female) diagnosed with CAD or aortic stenosis. Table 1 describes the sample characteristics. Risk factors for cardiovascular diseases were present in all nine patients. Other comorbidities, such as chronic renal insufficiency, rheumatic fever, stroke, chronic atrial fibrillation and acute myocardial infarction (AMI), were found in seven patients.

Table 1 - Baseline characteristics of the study population

\begin{tabular}{lc}
\hline Variables & $\mathbf{n}=\mathbf{9}$ \\
\hline Male gender, $\mathrm{n}(\%)$ & $8(88.9)$ \\
Age (years) & $62.4 \pm 6.3$ \\
Weight $(\mathrm{kg})$ & $88.4 \pm 10.8$ \\
Height $(\mathrm{cm})$ & $172.7 \pm 0.9$ \\
BMl $\left(\mathrm{kg} / \mathrm{m}^{2}\right)$ & $29.5 \pm 2.3$ \\
Normal weight, $\mathrm{n}(\%)$ & $1(12.5)$ \\
Pre-obese, $\mathrm{n}(\%)$ & $5(55.6)$ \\
Grade 1 obese, $\mathrm{n}(\%)$ & $3(33.3)$ \\
\hline
\end{tabular}

(To be continued) 
(Conclusion)

Table 1 - Baseline characteristics of the study population

\begin{tabular}{lc}
\hline Variables & $\mathbf{n}=\mathbf{9}$ \\
\hline CAD, $\mathrm{n}(\%)$ & $7(77.7)$ \\
Aortic stenosis, $\mathrm{n}(\%)$ & $2(22.2)$ \\
SAH, $\mathrm{n}(\%)$ & $9(100)$ \\
Smoking, $\mathrm{n}(\%)$ & $4(44.4)$ \\
Dyslipidemia, $\mathrm{n}(\%)$ & $2(22.2)$ \\
\hline
\end{tabular}

Note: BMI: Body Mass Index; CAD: Coronary artery disease; SAH: Systemic arterial hypertension.

The most often used surgical procedure was MRS. Only 2 patients underwent valve replacement. Table 2 depicts information about surgery and hospitalization. Blood products were used trans- and postoperatively by four patients who underwent MRS.

Table 2- Surgical procedure and hospitalization characteristics

\begin{tabular}{lc}
\hline Variables & $\mathbf{n}=\mathbf{9}$ \\
\hline MRS, $\mathrm{n}(\%)$ & $7(77.7)$ \\
Valve replacement, $\mathrm{n}(\%)$ & $2(22.2)$ \\
ECC (min) & $55.2 \pm 27.2$ \\
Perfusion (min) & $68.4 \pm 29.7$ \\
Hospitalization (days) & $12.6 \pm 8.1$ \\
ICU hospitalization (days) & $3.8 \pm 2.8$ \\
Number of drains & $1.8 \pm 0.6$ \\
Blood products, $\mathrm{n}(\%)$ & $4(44.4)$ \\
Transoperative complications, $\mathrm{n}(\%)$ & $4(44.4)$ \\
Complications at ICU, $\mathrm{n}(\%)$ & $6(66.6)$ \\
\hline
\end{tabular}

Note: MRS: Myocardial revascularization surgery; ECC: Extracorporeal circulation; ICU: Intensive care unit.

MMSE scores dropped from $24.46 \pm 3.3$ points in the preoperative period to $23.1 \pm 4.5$ points in the postoperative period (Figure 1). This reduction, however, was not statistically significant $(\mathrm{p}=0.461)$. Five patients had normal scores ( $\geq 25$ points) at baseline and another 5 patients had normal scores in the final assessment. The other patients had scores between 17 and 24 points. For patients who had normal scores in the final assessment, the mean ECC time was 45 minutes and the mean perfusion time was 59.4 minutes. Only 1 patient had normal MMSE scores at baseline, but MMSE scores compatible with moderate cognitive impairment in the final assessment.

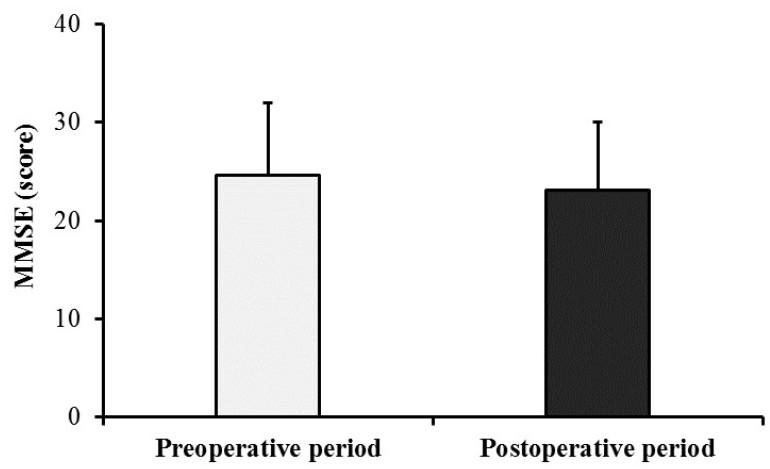

Figure 1 - Patients' pre- and postoperative Mini-Mental State Exam (MMSE) scores.

For patients who had normal MMSE scores at baseline and MMSE scores compatible with mild or moderate impairment in the final assessment, the mean ECC times was 73.5 minutes and the mean perfusion time was 86.5 minutes. None of the participants had dementia as a result of surgical procedure.

Patients' mean DASI scores also dropped from $23.1 \pm 13.9$ METs in the preoperative period to 4.8 \pm 2.5 METs in the postoperative period (Figure 2), revealing a significant functional loss during hospitalization $(p=0,003)$.

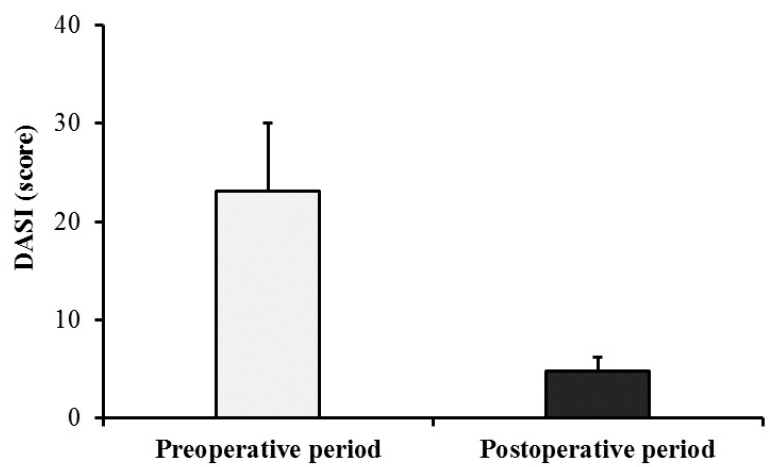

Figure 2 - Patients' pre- and postoperative Duke Activity Status Index (DASI) scores.

The mean estimated $\mathrm{VO}_{2}$ decreased from $19.5 \pm$ $5.9 \mathrm{~mL} \bullet \mathrm{kg}^{-1} \bullet \mathrm{min}^{-1}$ in the preoperative period to $11.6 \pm 2.1 \mathrm{~mL} \cdot \mathrm{kg}^{-1} \bullet \mathrm{min}^{-1}$ in the postoperative period (Figure 3). Consequently, the sample also exhibited a significant decrease in exercise capacity $(\mathrm{p}=0.003)$. 


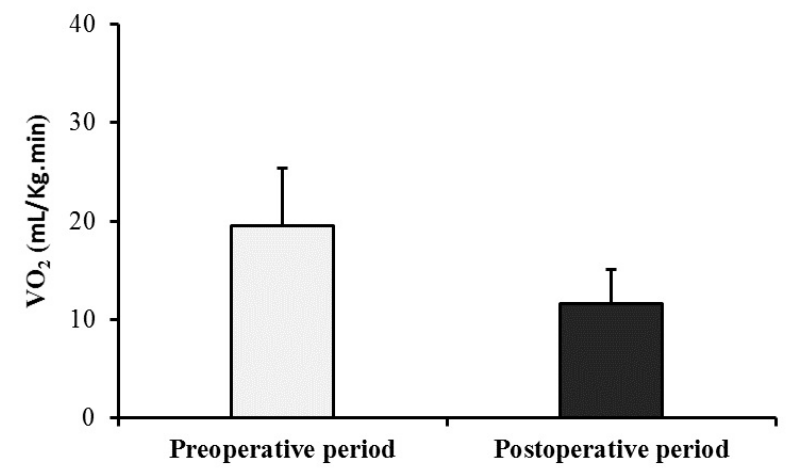

Figure 3 - Patients' pre- and postoperative oxygen uptake as estimated by the Duke Activity Status Index.

\section{Discussion}

This study found a significant reduction between pre- and postoperative DASI scores and $\mathrm{VO}_{2}$. Previous studies have shown that patients referred to undergo MRS are increasingly older and have other associated comorbidities. In line with this trend, the mean age of participants was 62 years and the underlying disease was associated with comorbidities in $77 \%$ of cases $(17,19-22)$.

Carrazedo et al. (11) assessed the cognitive performance of patients and found similar results. Most patients had worse cognitive function postoperatively. This is probably associated with previous AMI. In this study, 5 patients had previous AMI. No correlation, however, was found between this event and cognitive function.

Study participants undergoing valve replacement showed no cognitive deficits postoperatively. Nevertheless, studies on cognitive performance suggest this type of intervention is more detrimental to cognitive function than MRS, even in the case of replacement with biological prostheses $(23,24)$.

The correlation between ECC time and brain damage is well known and established in the literature. About $20-45 \%$ of patients develop a cognitive disorder after undergoing cardiac surgery. In this study, the mean ECC time was 55,2 minutes, which is considered normal $(<115$ minutes) in this kind of surgical procedure. Thus, the reduction in cognitive capacity cannot be associated with ECC time (17, 25 - 27).

A literature review discussed the main factors involved in neurological injury following cardiac surgery and assessed the pharmacotherapy used to prevent it (28). This study indicates that ECC and perfusion time is an intraoperative risk factor associated with the duration of the procedure.

In addition to assessing cardiac patients' cognitive impairment, it is also critical to assess their exercise capacity. It is known that the functional status of cardiac patients may be severely limited by reduced muscle mass and strength. A reduction in oxidative capacity and a significant decrease in blood flow affect the production of energy in the muscle. The Brazilian version of the DASI is a valid, reliable and easily administered instrument for self-assessing functional capacity in patients with cardiovascular diseases $(2,14,29)$.

Orvin et al. (15) investigated changes in the cognitive performance and functional status of older adults undergoing MRS. Assessments were performed at baseline and at 1 month postoperatively using the Medical Outcome Study Short Form -36 (MOS SF-36), the MMSE, the clock drawing test, the Color Trails Test (CTT), the Cognistat evaluation, the Barthel Index and the DASI. The study found positive functional performance and cognitive function results postoperatively. This agrees with this study, because patients were assessed in the initial (intra-hospital) phase of the CRP. We believe that administering the DASI at a more advanced phase of rehabilitation would result in better scores, especially in items related to household tasks and recreational tasks.

Gonçalves et al. (16) assessed quality of life of patients who participated in a CRP after MRS using the MOS SF-36 questionnaire at three time points: preoperatively, at 5 days and at 2 months postoperatively. There was a significant $(\mathrm{p}<0.001)$ reduction in body function $(41.9 \%)$ at discharge, with a recovery at 2 months postoperatively. These results corroborate the findings of this study, in which patients exhibited a $79.23 \%$ reduction in mean DASI scores postoperatively, evidencing significant functional loss before hospital discharge.

Morais et al. (20) assessed pain in the pre- and postoperative periods, both in the first surgery and reoperation. The study was conducted with cardiac patients undergoing cardiac surgery with ECC. Patients were assessed using the Functional Independence Measure (FIM) and the visual analogue scale (VAS) preoperatively and at 2, 3, 5 and 6 days postoperatively. There was a loss of functional performance from the preoperative period to days 2 and 3 postoperatively and a gain of functional performance from days 2 and 3 postoperatively to days 5 and 6 postoperatively $(p<0.001)$. These findings are in line with the results 
obtained in this study, in which patients' functional capacity was lower in the postoperative period, compared with the preoperative period.

Koch et al. (30) investigated the pre- and postoperative functional status of patients undergoing MRS. Older patients and patients who had chronic obstructive pulmonary disease, AMI, stroke, diabetes, vascular disease, severe postoperative infection and had to be returned to the operating room had lower postoperative scores. This study found similar results. Seven patients who had comorbidities and advanced age obtained lower postoperative than preoperative functional scores.

One limitation of this study was the issue of how to deal with respondents' failure to answer MMSE questions due to their illiteracy. Owing to patients' short hospital stay, it was not possible to assess exercise capacity using other instruments such as the six-minute walk test (MWT). Moreover, their clinical status usually did not allow for performance of other exercise capacity tests.

\section{Conclusion}

This study demonstrated a loss of exercise capacity - but no cognitive changes - after cardiac valve replacement or myocardial revascularization surgery.

\section{References}

1. Santos CA, Oliveira MAB, Brandi AC, Botelho PHH, Brandi JCM, Santos MA, et al. Risk factors for mortality of patients undergoing coronary artery bypass graft surgery. Rev Bras Cir Cardiovasc. 2014;29(4):513-20.

2. Santos KMS, Cerqueira Neto ML, Carvalho VO, Santana Filho VJ, Silva Jr WM, Araújo Filho AA, et al. Evaluation of peripheral muscle strength of patients undergoing elective cardiac surgery: a longitudinal study. Rev Bras Cir Cardiovasc. 2015;29(3):355-9.

3. Teixeira SM, Guirado GN, Silva MAM. Preoperative therapy restores ventilatory parameters and reduces length of stay in patients undergoing myocardial revascularization. Rev Bras Cir Cardiovasc. 2014; 29(2): 221-8.
4. Uncu H, Acipayam M, Altinay L, Dogan P, Davarci I, Özsöyler I. The effect of gender on the early results of coronary artery bypass surgery in the younger patients group. Rev Bras Cir Cardiovasc. 2014;29(4): 569-73.

5. Park H, Hong YJ, Rhew SH, Kim SS, Jeong YW, Jeong HC, et al. Effect of revascularization strategy in patients with acute myocardial infarction and renal insufficiency with multivessel disease. Korean J Intern Med. 2015;30(2):177-90.

6. Fernandes MAS, Bitencourt LS, Lessa IN, Viana A, Pereira F, Bastos G, et al. Impacto do perfil socioeconômico na escolha da prótese valvar em cirurgia cardíaca. Rev Bras Cir Cardiovasc. 2012; 27(2): 211-6.

7. Pivatto Jr F, Teixeira Filho GF, Sant'anna JRM, Py PM, Prates PR, Nesralla IA, et al. Idade avançada e incidência de fibrilação atrial em pós-operatório de troca valvar aórtica. Rev Bras Cir Cardiovasc. 2014; 29(1):45-50.

8. Lai KSP, Herrmann N, Saleem M, Lanctôt KL. Cognitive Outcomes following Transcatheter Aortic Valve Implantation: A Systematic Review. Cardiovasc Psychiatry Neurol. 2015; 2015(1):1-8.

9. Matheus GB, Dragosavac D, Trevisan P, Costa CE, Lopes MM, Ribeiro GCA. Treinamento muscular melhora o volume corrente e a capacidade vital no pós-operatório de revascularização do miocárdio. Rev Bras Cir Cardiovasc. 2012;27(3):362-9.

10. Fonseca L, Vieira FN, Azzolinc KO. Fatores associados ao tempo de ventilação mecânica no pós-operatório de cirurgia cardíaca. Rev Gaúcha Enferm. 2014;35(2): 67-72.

11. Carrazedo MA, Accetta GG, Pinto RASR, Costa FAA. Avaliação Cognitiva em Pacientes Submetidos à Revascularização Cirúrgica Cardíaca. Rev Bras Cardiol. 2014;27(4):254-9.

12. Oliveira JMA, Silva AMF, Cardoso SB, Lima FF, Zierer MS, Carvalho ML. Complicações no pós-operatório de cirurgia cardiovascular com circulação extracorpórea. R Interd. 2015; 8(1):9-15.

13. Pereira EEB, Souza ABF, Carneiro SR, Sarges ESNF. Funcionalidade global de idosos hospitalizados. Rev Bras Geriatr Gerontol. 2014; 17(1):165-76. 
14. Coutinho MA, Dias RC, Fernandes AA, Araújo CG, Hlatky MA, Pereira DG, et al. Duke Activity Status Index em Doenças Cardiovasculares: Validação de Tradução em Português. Arq Bras Cardiol. 2014;102(4):383-90.

15. Orvin K, Dvir D, Weiss A, Assali A, Vaknin-Assa H, Shapira Y, et al. Comprehensive prospective cognitive and physical function assessment in elderly patients undergoing transcatheter aortic valve implantation. Cardiology. 2014;127(4):227-35.

16. Gonçalves FDP, Marinho PEM, Maciel MA, Galindo Filho VC, Dornelas AA. Avaliação da qualidade de vida pós-cirurgia cardíaca na fase i da reabilitação através do questionário MOS SF-36. Rev Bras Fisioter. 2006;10(1):121-6.

17. Joudi M, Fathi M, Harati H, Joudi M, Izanloo A, Rahdari A, et al. Evaluating the Incidence of Cognitive Disorder Following Off-Pump Coronary Artery Bypasses Surgery and its Predisposing Factors. Anesth Pain Med Tehran. 2014;4(4): e18545.

18. Almeida OP, Crocco EI. Percepção dos déficits cognitivos e alterações do comportamento em pacientes com doença de Alzheimer. Arq Neuropsiquiatr. 2000;58 (2A):292-9.

19. Tavares LA, Barreto-Neto J, Jardim JR, Souza GMC, Hlatky MA, Nascimento AO. Adaptação cultural e avaliação da reprodutibilidade do Duke Activity Status Index para pacientes com DPOC no Brasil. J Bras Pneumol. 2012; 38(6):684-91.

20. Morais DB, Lopes ACR, Sá VM, Silva Jr WM, Cerqueira Neto ML. Avaliação do Desempenho Funcional em Pacientes Submetidos à Cirurgia Cardíaca. Rev Bras Cardiol. 2010;5(23):263-9.

21. Kaplan HI, Sadock BJ. Kaplan and Sadock's Synopsis of Psychiatry. Philadelphia: Lippincott Williams and Wilkins; 2003.

22. Nina VJS, Rocha MIA, Rodrigues RF, Oliveira VC, Teixeira JLL, Figueredo ED, et al. Avaliação do escore CABDEAL como preditor de disfunção neurológica no pós-operatório de revascularização miocárdica com circulação extracorpórea. Rev Bras Cir Cardiovasc. 2012; 27(3):429-35.
23. Teixeira SV, Costa C, Costa A, Grangeia R, Reis C, Coelho R. Disfunção neurocognitiva após cirurgia valvular. Acta Med Port. 2008;21(5):475-82.

24. Zimpfer D, Czerny M, Schuch P, Fakin R, Madl C, Wolner $\mathrm{E}$, et al. Long-term neurocognitive function after mechanical aortic valve replacement. Ann Thorac Surg. 2006; 81(1):29-33.

25. Rolfson DB, McElhaney JE, Rockwood K, Finnegan BA, Entwistle LM, Wong JF, et al. Incidence and risk factors for delirium and other adverse outcomes in older adults after coronary artery by- pass graft surgery. Can J Cardiol. 1999;15(7):771-6.

26. Chaput AJ, Bryson GL. Postoperative delirium: risk factors and management: continuing professional development. Can J Anaesth. 2012;59(3):304-20.

27. Mu DL, Wang DX, Li LH, Shan GJ, Su Y, Yu QJ, et al. Postoperative delirium is associated with cognitive dysfunction one week after coronary artery bypass grafting surgery. Beijing Da Xue Xue Bao. 2011; 43(2):242-9.

28. Martin VFJ, Melo VOR, Sousa PL. Disfunção cognitiva após cirurgia cardíaca. Rev Bras Cir Cardiovasc. 2008;23(2):245-55.

29. Tang HW, Topol JE, Fan Y, Wu Y, Cho L, Stevenson C, et al. Prognostic value of estimated functional capacity incremental to cardiac biomarkers in stable cardiac patients. J Am Heart Assoc. 2014;3(5):e000960.

30. Koch GC, Khandwala F, Cywinski BJ, Ishwaran H, Estafanous F, Loop DF, et al. Health-related quality of life after coronary artery bypass grafting: A gender analysis using the Duke Activity Status Index. J Thorac Cardiovasc Surg. 2004;128(2):284-95.

Received in 03/09/2016
Recebido em 09/03/2016
Approved in 04/04/2017
Aprovado em 04/04/2017 